\title{
EDUCATIONAL AND DEVELOPMENTAL ENVIRONMENT AS A FACTOR OF SKILLS FORMATION OF SELF-ORGANIZATION OF PRIMARY SCHOOL PUPILS' EDUCATIONAL ACTIVITY
}

\begin{abstract}
Volodymyr Chaika ${ }^{1}$, Oksana Pysarchuk ${ }^{2}$, Olha Chykurova ${ }^{3}$
${ }^{I}$ Doctor of Science (pedagogy), Professor, Department of Pedagogy and Methods of Primary and Preschool Education, Ternopil National Pedagogical University named after Volodymyr Hnatyuk, Ternopil, Ukraine, e-mail: chaikavm2704@gmail.com ORCID: https://orcid.org/0000-0003-3665-0403

${ }^{2}$ Ph.D. (pedagogy), Lecturer, Department of Pedagogy and Methods of Primary and Preschool Education, Ternopil National Pedagogical University named after Volodymyr Hnatyuk, Ternopil, Ukraine, e-mail: pysarchukoksana04@gmail.com ORCID: https://orcid.org/0000-0003-0110-9174

${ }_{3}$ PhD-student, Department of Pedagogy and Methods of Primary and Preschool Education, Ternopil National Pedagogical University named after Volodymyr Hnatyuk, Ternopil, Ukraine, e-mail: o.teslyuk@gmail.com ORCID: http://orcid.org/0000-0003-4760-9895
\end{abstract}

Abstract. Modernization of educational activities determines the necessity for the formation of educational and developmental environment. Today, the development of students' self-organization in an educational and developmental environment is one of the main demands that modern society puts forward to the system of primary education. The purpose is to study the features of the educational and developmental environment, its classification; development of didactic games at the lessons of Writing and Mathematics that promote the development of pupils' self-organization in an educational and developmental environment. Research methods: a logical method; methods of system analysis; comparative analysis has made it possible to compare phenomena in order to establish similarities or differences between them. The academic paper has highlighted the essence of the concepts "educational and developmental environment", "self-organization of educational activities". The components of the educational and developmental environment of primary school and its classification have been formed. The basic types of primary pupils' self-organization under the influence of the educational and developmental environment have been considered. The stages of the ability of self-organization of primary schoolchildren's educational activity within the conditions of educational and developmental environment have been determined. Examples of Writing lessons in grades 1 and 4 have been given at the above stages, which contribute to the formation of skills of self-organization of pupils' learning activities. Thus, types of didactic games at the lessons of Writing and Mathematics have been offered, which make it possible to provide material in accessible, interesting form, form skills of self-organization of schoolchildren in educational environment.

Key words: personality, child, primary schoolchildren (pupils), teacher, game activity, cognitive activity, independence.

JEL Classification: JEL I0; I20

Formulas: 0; fig.: 2; tabl.: 0; bibl.: 14 .

Introduction. Transformation of the primary education system determines the need for the formation of educational and developmental environment in the process of educational activities. This will provide the preconditions for pupils to fully acquire the system of scientific knowledge, skills and abilities. Therefore, the development of pupils' self-organization is one of the main demands that modern society puts forward to education. According to the Concept of the New Ukrainian School (NUS) "the basic result centers around the formation of general learning skills that provide the opportunity to continue education at middle school, mastering the ability to learn - the ability to self-organize in order to solve educational issues". The amount of information doubles every year. Knowledge becomes obsolete faster than a 
person has time to use it. In order to successfully live and act in the modern world, it is necessary to be constantly ready for change, while maintaining your own uniqueness. The basic goal of primary school is to teach pupils activity and educational independence, self-organization. This, in turn, highlights the issue of organizing purposeful work on the development of self-organization of primary schoolchildren.

Literature Review. The issue of "educational and developmental environment" has been covered in the works of such scientists as: I. Karabayeva, N. Kichuk (Kichuk, 2016), I. Kostyuk (Kostyuk, 2016), O. Kokhanova (Kokhanova, 2012), Yu. Manuilov, L Novikova, O. Savchenko (Savchenko, 2012), O.P. Sergeenkova (Sergeenkova, 2012), O. Stolyarchuk (Stolyarchuk, 2012), O. Pasek (Pasek, 2012), V. Petrovsky, I. Rachenko (Rachenko, 1972), A. Tsymbalaru, K. Shevchenko (Savchenko, 2012), V. Yasvin (Yasvin, 2001). The classification of educational and developmental environment has been given in the researches of such scholars as: Ye. Bondarevskaya, V. Vesnin, I. Levitskaya, S. Smolyuk (Smolyuk, 2016; Smolyuk, 2017). The works of S. Amirov, G. Gmyzin, L. Zhuravlyova (Zhuravlyova, 2018), O. Ishkov, G. Kogan, S. Kulnevych, V. Lvovich, S. Menkova (Menkova, 2019), N. Rybakova, L. Faleyeva (Faleyeva, 2012), J. Ustinova, etc., are devoted to the issue of self-organization of educational activity.

In Ukraine, at present time, quite a lot of attention is paid to the issues of education and upbringing of children, while researches, aimed directly on the educational and developmental environment and the process of self-organization of educational activities of primary school pupils, are not enough.

Aims. The purpose of the academic paper is to study the features of the educational and developmental environment, its classification, as well as the basic types and stages of formation of self-organization of primary schoolchildren; development of didactic games at the lessons of Writing and Mathematics that promote the development of pupils' self-organization in an educational and developmental environment.

Methods. A logical method has been used to reveal the content of the educational and developmental environment and self-organization of educational activities; methods of system analysis have been applied to identify structural links between the stages of formation of self-organization of primary school pupils; comparative analysis has made it possible to compare phenomena in order to establish similarities or differences between them.

Results. In the modern school the child learns to make a choice, to freely express the will, reveals himself as a person. The child develops best when he is fascinated by the learning process and takes an active part in the activities. Practice shows that the full development of the child is possible only in a specially created educational environment, which is a system of material objects of the child. It functionally models the content of his spiritual and physical development.

According to viewpoint of I. Kostyuk, the educational and developmental environment is a system of conditions and influences that contribute to the active 
development, learning, promoting the child's personality, his ability to work independently, the ability to adapt to changes (Kostyuk, 2016).

Scientists I. Karabayeva, K. Krutiy, O. Savchenko define the educational and developmental environment as a set of certain conditions, influences, associations of subjects of education that provide development, training, education of the individual, his self-awareness (Savchenko, 2012).

From the point of view of V. Shuldyk, K. Shevchenko, the developmental educational environment is considered as a sphere of personal growth, human life, interaction of informational, cognitive, psychological, pedagogical accumulation of knowledge, where purposeful development of personality is carried out (Shevchenko, 2014).

Modern researcher S.V. Smolyuk interprets the developmental educational environment of primary school as an integrative concept that synthesizes a number of psychological, pedagogical, logistical, sanitary, didactic, ecological and aesthetic and other factors, as a result of interaction of which effective socialization and development of personal values of the pupil in educational process of primary school is provided (Smolyuk, 2017).

A number of scientists, studying the features of the formation of educational and developmental environment, consider its impact on development, while other researchers agree that the basis of the educational system in modern conditions and the direction of pedagogy are humanistic values. Thus, according to viewpoint of V. Yasvin, in order for the educational environment to have a developmental character, it must provide a set of opportunities for self-development of the subjects of the educational process (children and teachers). This complex includes three structural components: spatial-objective (classroom); social (nature of interaction of subjects of educational activity); psychodidactic (content and methods of teaching, due to the purpose and objectives of the educational process) (Yasvin, 2001).

The conducted analysis provides grounds for the formation of one's own vision of the educational and developmental environment, as a set of social-psychological, pedagogical, informational, technical factors that provide the prerequisites for the formation and self-realization of the individual. It should meet the characteristics and needs of the educational process, pedagogical technologies used and, above all, to ensure the nature of learning.

It should be noted that a number of psychological aspects and patterns must be taken into account in the course of formation of the educational and developmental environment (Figure 1).

During the formation of the educational and developmental environment there is a positive emotional atmosphere and the development of interest in learning activities. Scientists O. Sergeenkova, O. Stolyarchuk, O. Kokhanova, O. Pasekova claim that the problem in organizing the educational process of primary schoolchildren lies in the fact that they do not accept the goal set by the teacher when realizing the importance of education; therefore, the goal set by the teacher for primary pupils does not become their own goal (Sergeenkova, Stolyarchuk, Kokhanova \& Pasek, 2012). 
Psychological aspects and patterns of formation of the educational and developmental environment in the system of primary education

\begin{tabular}{|l|l|}
\hline $\begin{array}{l}\text { The factors of formation of the educational and developmental environment } \\
\text { are the components of the living space of the individual as a specific physical } \\
\text { environment, social-cultural circumstances that determine the general structure } \\
\text { and rhythm of life }\end{array}$ \\
$\longrightarrow \begin{array}{l}\text { The educational environment should be an open system and ensure the } \\
\text { dialogicity of all pupils' contacts }\end{array}$ \\
$\longrightarrow \begin{array}{l}\text { Providing space for full expression of individual and age capabilities of } \\
\text { primary school pupils }\end{array}$ \\
$\begin{array}{l}\text { The attitude of the personality of a primary school pupil to the educational } \\
\text { environment contributes to the acceptance of the values of the educational } \\
\text { organization as their own personal beliefs }\end{array}$ \\
\hline Psing
\end{tabular}

\section{Fig. 1. Psychological aspects and patterns of formation of educational and developmental environment in the system of primary education}

Source: author's development based on (Kostyuk, 2016)

The creation of a positive emotional atmosphere and the development of interest in learning is facilitated by the formation of the indisputable authority of the teacher for primary schoolchildren, which ensures the transition of the goal set by the teacher to the child's own goal of learning. Psychologists distinguish the following principles of forming the authority of the teacher, namely: the dissemination of the authority of all adults for the child, the recognition of the teacher as a carrier of numerous knowledge, the organizer of school activities, perception of the teacher as a subject of assessment and educational impact on the child (Smolyuk, 2016).

In this regard, there is a need to provide primary pupils with the opportunity to carry out various activities, such as: individual learning, gaming, artistic and aesthetic, labor, sports, research, creative and project activities, educational cooperation. In order to implement the outlined, the school needs an educational and developmental environment that includes:

- technical equipment of classrooms (computer equipment, including hardware, access to Internet resources);

- digital educational resources (electronic simulators on subjects, textbooks, educational Internet portals);

- educational and methodical literature (textbooks for schoolchildren, reference books, dictionaries and textbooks, methodical support for teachers);

- educational - practical and laboratory equipment (visual equipment, devices, tools, natural objects, models, etc.).

Rationally organized educational and developmental environment makes it possible for each child to find an interesting activity, believe in his abilities, learn to interact with adults and peers. When creating a developmental environment at 
primary school, it is necessary to rely on the principles of openness, versatility, flexible zoning, stability and dynamism (Kichuk, 2016).

The peculiarity of studying at primary school determines the real possibility of using intersubject connections, interlinks of classroom and extracurricular activities. The classroom (especially for first-graders) should be equipped not only with traditional educational equipment; it should also provide space, the organization and use of which is a necessary condition for maintaining and strengthening the health of primary schoolchildren.

The educational activity of primary pupils in relation to game becomes leading, and formation of ability to study is carried out in the form of a lesson and training classes. Extracurricular educational activities are used in practice in order to create conditions for the child's advancement in the educational space, the formation of his educational independence, self-organization, which also makes it possible to expand his own knowledge, skills, and competences. Extracurricular activities of pupils unite all types of activities of primary schoolchildren, in which it is possible and appropriate to solve the issues of their education and socialization. Types and forms of extracurricular activities are determined independently in each educational organization, taking into account the available potential and resources.

Equipping an extracurricular playroom makes it possible for primary school teachers to organize children's leisure time during shifts. Children learn here to independently determine the content of their activities, allocate time and actively participate in activities. The organization of a children's playroom at school allows pupils to be freely engaged in various activities at the same time, according to their interests and desires. Classes in this area have a positive effect on the general condition of the child, create a positive mood, relieve emotional stress.

In this connection, the educational and developmental environment of primary school can be represented by:

- educational area with magnetic and interactive whiteboards, computers, projector, stands, which include educational and organizational (optimal organization of pupils' places, teacher's places), educational-intellectual (schemes, interesting stands on subjects or themes, puzzles, crossword puzzles, corners "Chomuchka", "Questions and answers", "Interesting mathematics, "Do you know?", etc.), educational and informational rubrics.

- sports and recreation area or a healthy lifestyle area to relieve fatigue, static stress, hypodynamics. The sports and recreation area should be equipped with a gymnastic wall with a gymnastic board, massage mats, soccer and basketball balls, plastic dumbbells, skittles, skipping ropes, a ball pool, etc. Inflatable balls are very popular among children, the variety of ways of application of which make them one of the favorite types of sports and game equipment.

The efficiency of the sports and recreation area is very high. School pupils' lounge zones and the gym should provide pupils with the opportunity to implement their physical activity, forasmuch as one of the most important activities is to create a comfortable health environment. 
Here one can observe the information under the headings: healthy lifestyle, traffic rules, basics of life safety.

- a play area equipped, taking into consideration a gender perspective. At school, in the context of story-based role-playing, rules-based gaming activities and highlevel directorial gaming activities, it is necessary to create conditions for the gradual transition of children from full-fledged gaming activities to educational activities, and to compensate the insufficient development of gaming activities for some children in the class.

- information zone - located on the perimeter of the classroom; it is represented by stands on the walls. The content of the stands reflects the life of Ukraine, as well as the hometown. Information for parents can be posted here. Stands are decorated in color, which makes you want to get acquainted with the information.

- correctional (social) zone, designed to correct disorders of mental processes of pupils. Correction area, or zone of developing games, aimed at both individual and group work (didactic games, games for the development of sensorimotor processes, games that promote the development of cognitive processes: mosaics, puzzles, lacing, games with free-flowing materials).

- rest area. Most children stay at school until 2.30 p.m. 5 days a week. It is advisable to make the space of the game room more homely. There may be a TV, DVD player in the rest zone. During rest it is possible to include pleasant music, to carry out musical physical training minutes. Children like listening to and singing children's songs.

- "Crazy hands" area - is an exhibition of children's products and drawings. Works need to be updated. Creating such a zone helps the child feel his significance, increases his self-esteem.

- "World of Nature" area, which comprises material that promotes the formation of pupils' ideas about life on earth, about natural communities, about the development and adaptation of living organisms to the environment.

- green area, which is represented with a variety of decorative flowers, information cards about flowers (flower name, family, etc.). The presence of flowers in the classroom makes it possible to form the skills and desires of children who care for them, to cultivate diligence, instill love and respect for nature. In addition, it makes it possible to create a cozy and comfortable learning space.

Taking in consideration the above, the educational and developmental environment of primary school creates all the necessary conditions for the formation of skills of self-organization of pupils' educational activities. The term "selforganization" was first used by W. Ashby in 1947, and in the domestic literature I.R. Prigozhin used this term in the 50-60s to describe the process of thermodynamics. By the way, L.V. Faleyeva consideres the self-organization of activities as a system of abilities and skills to mobilize the capabilities of the individual to achieve a personally or socially significant goal, which allow the pupil to be the subject of their own educational activities. The latter involves the identification and activation of the subject's own psychophysiological abilities and opportunities for purposeful activity (Faleeva, 2012). 
Thus, self-organization is understood as the process during which the creation, reproduction and improvement of a complex management system is carried out. Selforganization is a complex property, which is expressed in freedom from external factors and coercion, the ability to subordinate his own views to own behavior, willingness to carry out activities without any assistance. When talking about the formation of pupils' self-organization, it is necessary to keep in mind two interrelated objectives:

The first objective centers on developing pupils' independence in cognitive activity; it is necessary to teach them to master knowledge, to form their own worldview;

The second objective centers on teaching children to independently apply the acquired knowledge in learning and practice.

Herewith, the basic types of self-organization of primary schoolchildren under the influence of the educational and developmental environment are distinguished, which are reflected in Fig. 2.

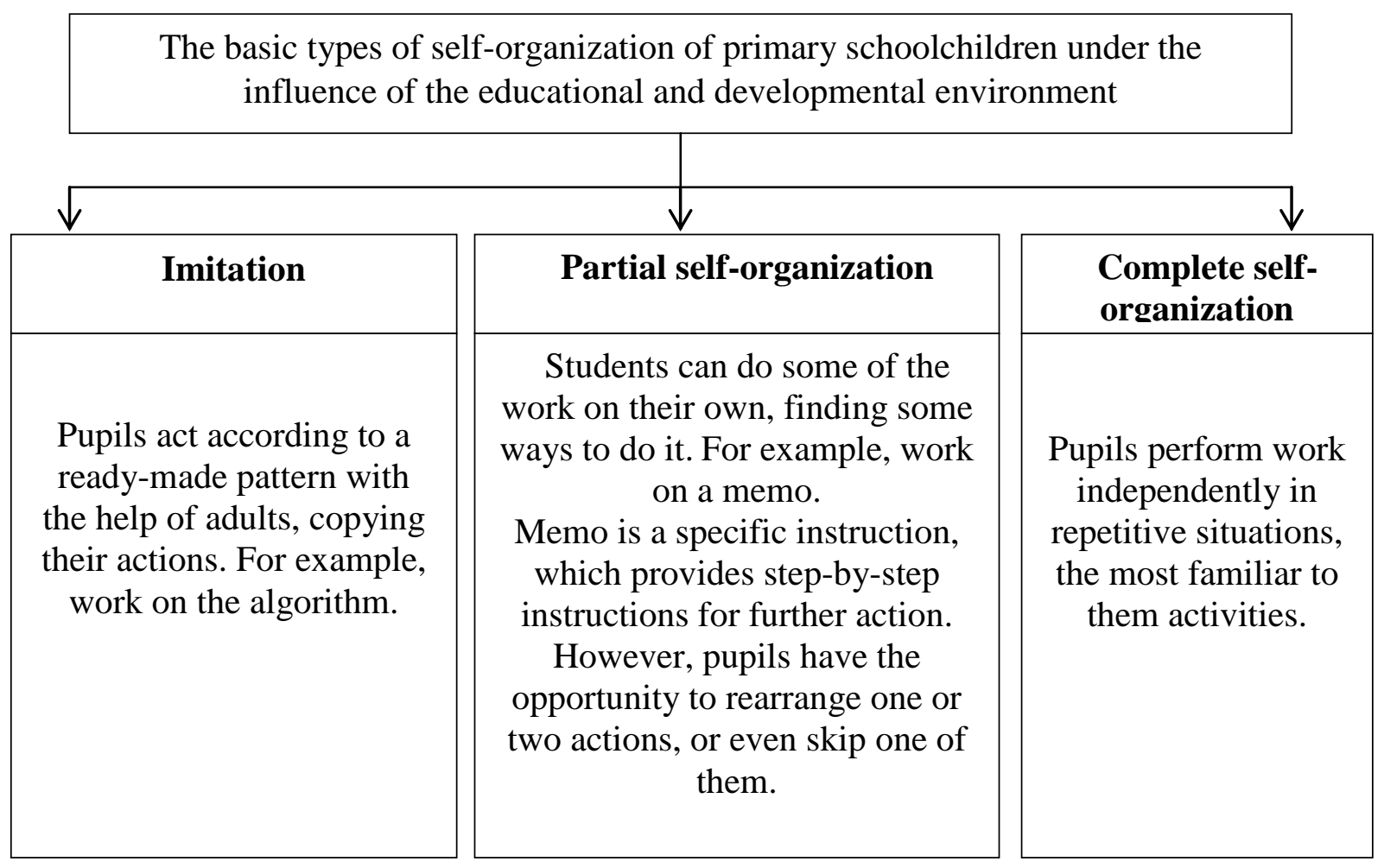

\section{Fig. 2. The basic types of self-organization of primary schoolchildren under the influence of the educational and developmental environment}

Source: author's development based on (Menkova, 2019; Zhuravlyova, 2018)

In the scientific literature, the following stages of ability of self-organization of educational activity of primary school pupils within the conditions of the educational and developmental environment are allocated, namely (Menkova, 2019):

- the ability to determine the purpose of the educational task;

- the ability to plan the educational task;

- the ability to properly perform the educational task; 
- the ability to control the course and results of the educational task;

- the ability to assess the course and results of the educational task.

The ability to determine the purpose of the educational task. The purpose is considered as a pedagogical category in the works of K.D. Ushynsky, N.K. Krupskaya, A.S. Makarenko, B.A. Sukhomlynsky and others. In numerous scientific articles considerable attention is given to the issue of purpose setting. Thus, the starting point in becoming a pupil as an organizer of cognition is to determine the purpose. According to viewpoint of I.P. Rachenko, the purpose determines not only the general direction and effective stage of work, but also all intermediate links. And this determines the organization of all activities (Rachenko, 1972).

The purpose for the pupil is activity orientation. Finding out the purpose by pupils creates a certain emotional state, mobilizes volitional efforts. The purpose should be recognized. In the learning process, the purpose and objectives of future activities are usually set to pupils from the outside. As a rule, the teacher organizes and directs the actions of pupils. This leads to the fact that often the purpose of learning management is formed from the learning process of primary school pupils.

At different levels (during the analysis of new material, when checking homework), it is desirable to first direct pupils to understand the purpose set by the teacher, then to self-statement of their own purpose, which has a personal meaning.

We propose to consider this stage on the example of the lesson of Writing in 1st grade on the topic "Rules of carry over".

Teacher: Guess the riddle (the riddle about the birch (bereza) is written on the board).

Pupils: Birch (bereza).

Teacher: I will write the answer on the board (continues writing, but the word does not fit on the board). What can I do, children?

Pupils: Carry over.

Teacher: Will you help me carry over the word birch (bereza), work in pairs. (Students work in pairs on sheets.)

Teacher: Let's see how you have carried over the word "birch" (bereza) (consider different options: (be-reza, bere-za, bere-za, ber-eza). The task was one; however, you have done it differently. Why did it happen?

Pupils: We don't know the rules.

Teacher: Consequently, what is the topic of our lesson?

Pupils: Carrying over of words.

Teacher: What is our goal?

Pupils: To learn the rules of carrying over of words.

Thus, defining the purpose of educational activities by pupils is not as a simple task as it may seem at first glance. This process requires a creative approach, a broad view of things, the activity of pupils' thinking.

Therefore, the conclusion can be done: the definition of purpose is a personal function that provides the process of constructing an imaginary image of the future result of the activity (purpose), awareness and subjective acceptance of this image, as well as regulation of the subject's own activities aimed at achieving this purpose. 
The ability to plan the educational task. The concept of "plan" is interpreted as a pre-planned system of activities that provides the order, sequence and timing of work. A sound plan is a working project of any activity. It is possible to measure process and results of work with its help. It can also act as a criterion for assessing the results of work.

We propose to consider this stage of the work on the example of the lesson of Ukrainian language in the 4th grade: monitoring dictation with visual training.

Teacher: Today at our lesson we will write a dictation on "Unstressed vowels in the endings of adjectives".

Pupils: Let's make a plan of our learning activities together at this lesson.

Pupils with the help of the teacher make a lesson plan: reading the text from the board; finding words with spelling - unstressed vowels in the endings of adjectives; finding words with other familiar spellings; explanation of spelling words; re-reading the text; explanation of the location of the comma; independent reading of the text; writing at teacher's dictation.

In addition, the development of the competence "self-organization of educational activities" is carried out directly in the organization and conducting independent work. At the initial stage, the teacher helps pupils make a plan of work and its implementation. Gradually, these actions are brought to automatism and do not require teacher's intervention.

The success of educational activities largely depends on the ability of primary pupils to predict future actions, the ability to identify different options for the task, analyze the features of each option and choose the best, the ability to properly perform the educational task. When the pupil has completed the oriented and planning part of the activities that make it possible for him to proceed to the direct implementation of the planned actions - he has decided at the stage of the educational task (Zhuravlyova, 2018).

This stage means directly independent work of pupils; it is one of the forms of the lesson. Let's consider in more detail the organization and procedure of conducting independent work at primary school.

Teacher: Today at the lesson we will write an independent work on the topic of "Carrying over of words". Let's define the purpose of this lesson.

Pupils: We'll repeat the studied material on the topic "Carrying over of words"; check knowledge on this topic; clarify and summarize the knowledge gained.

Teacher: Well done. Let's make the plan of work.

Pupils: 1) we read all the tasks of independent work;

2) we give a preliminary assessment for ourselves (we draw a man on a ladder).

This man symbolizes a certain assessment.; If a child draws the man on the top rung of a ladder, he assesses his work highly; if on average - doubts whether he will be able to do the job without mistakes; if at the bottom - believes that he will not be able to cope with this type of work;

3) we put the numbers in order and perform each task;

4) we check all the work again; 
5)we assess the work and set a score on a linear scale for ourselves. It is a vertical line with three horizontal distributions, symbolizing high, medium and low levels.

Teacher: What questions have arisen during preparation for independent work (testing)? If there are no questions, then let's start its implementation.

The ability to control the course and results of the educational task. Control is considered as a component of educational activities, which consists in the analysis and regulation of its course and outcomes. According to the learning process, selforganization is considered as an important component of the pupil's learning activities, which consists in the analysis and regulation of its course and results, as the ability to control his learning activities and correct mistakes.

Also, the formation of pupils' control over the course, the correctness of each operation and their sequence is not only a means of mastering each operation and their sequence, that is, not only a means of mastering educational material, but also a means of forming the attention of primary pupils (Menkova, 2019).

The ability to assess the course and results of the educational task. After completing the work, the teacher collects notebooks. The checking is carried out in two stages:

1) deferred control: the work is checked without grading. The teacher indicates in the fields the number of mistakes made in the work with red pen, without correcting the mistake itself. The notebooks are then returned to the pupils, who are looking for and correcting their mistakes by themselves.

2) final control: grades will be given on the same linear scale where pupils put grades (marks) for themselves.

After that a general analysis and adjustment of independent work (testing) is carried out. The teacher summarizes: what tasks have been done without mistakes, what tasks have been done without mistakes, who has done well, which tasks have been the most difficult. The teacher should explain do everything and the pupil, as a result, should understand where and why he has made mistakes.

Pupils' awareness of their mistakes leads to their most effective elimination. After analysis and correction of knowledge, pupils return to the previous assessment of their work (a man on a ladder). Now the man is put again. If the location of the men coincides, then the child adequately assesses the level of his knowledge and skills. However, practice has revealed that adequate self-esteem is very rare for primary school pupils; it is more often either underestimated or overestimated. The proposed organization of work not only leads to the effective development of the competence "self-organization of educational activities" of primary schoolchildren, but also corrects their self-esteem.

Thus, mastering the skills of self-organization of educational activities by primary schoolchildren is a mandatory minimum.

It should be mentioned that primary school children, especially first graders, are distinguished by high cognitive activity. In search of an answer to the endless "why and how", the child is willing to perform practical actions with objects that interest him. Primary schoolchildren are dominated by involuntary attention and memory. 
This feature determines the frequent change of activities and the inclusion of the game in the learning process.

Currently, numerous primary school teachers understand the importance of using gaming activities in the learning process of primary schoolchildren and the formation of their self-organization skills. For instance, at the lesson of Writing in the game "Who's more?" children independently come up with words for a given sound. In the game "Find the word in the word" pupils compose words from the letters of the word provided by the teacher. For the same purpose the games "Find a couple" (choose synonyms for words), "Add a word" and others are used.

At the lessons of Mathematics, one can use the didactic game-assignment "The fastest postman" in order to consolidate the knowledge of the table of addition and subtraction within 10 and the table of multiplication. The teacher gives the same number of cards ("letters") to 5 pupils, on the back of which expressions for addition and subtraction (multiplication or division) are written. Children, sitting at desks, draw houses with numbers (they hold in their hand the numbers from 1 to 10, or the answers of the multiplication table). Postmen should quickly identify the № of the house on the envelope (find the value of the expression) and deliver the letters to the appropriate houses (give to children who have cards with numbers indicating the answers to the expressions written on the envelopes). A pupil, who quickly and correctly delivers the letters to the destination, will be the fastest postman.

Thus, game technologies make it possible to present the educational material in the accessible, interesting, bright and figurative form, promote the best mastering of knowledge, cause interest to knowledge, form skills of self-organization of pupils.

Discussion. Proper organization of the lives and activities of children at primary school, regardless of their abilities means creation an educational environment that will meet the personal, cognitive, social and communicative development of each child. The role of the pupil and the teacher are clearly changing within the conditions of a developing educational environment. The teacher is the organizer of the pupil's development. He knows how to give knowledge to the child, and should organize a lesson for the development of regulatory, communicative, cognitive and personal learning activities. Teacher is a facilitator in mastering pupils' competences. He accompanies the child, creating conditions not only for the acquisition of subject knowledge, but, most importantly, for its self-organization. That is, the pupil from the passive, contemplating gradually becomes independent, and thinking.

The educational environment of primary school has significant development potential. It promotes the implementation of hidden creative talents and abilities of children, provides a constant high interest in knowledge, as well as provides a successful adaptation and a smoother transition to middle school. Creating and improving the educational and developmental environment of primary school in modern conditions is possible and necessary.

Conclusions. Thus, formation of skills of self-organization of primary schoolchildren in the conditions of the educational and developmental environment opens opportunities and ways of formation of the person; ways to identify the 
interests, inclinations, abilities of the child. The basic activities (game, study, work, communication) act as a means of formation and development of all its forces, properties, abilities, skills. The basic elements of self-organization of the personality are: self-knowledge, self-development, self-education, self-learning. Mastering the elements of mental activity is carried out, namely: comparison, the analysis, and synthesis; correct organization of relationships and interactions in the teaching staff; development of abilities and ability to convince people by word and deed; formation of self-characteristics and long-term plan of self-organization.

A promising area of further research is the use of information technology in the formation of skills of self-organization of educational activities of primary school pupils.

\section{References:}

1. Zhuravlyova, L.S. (2018). The problem of organizing independent activities of students in primary school: socio-pedagogical aspect. International scientific conference, Kaunas, Lithuania, 23-26.

2. Kichuk, N.V. (2016). Creating an educational environment for primary school students is a personal and professional purpose of a modern school teacher. Proceedings. Series: pedagogy,1, 6-10.

3. Kostyuk, I. (2016). Formation of educational and developmental environment in the lessons of literary reading in primary school. Pedagogical sciences: theory, history, innovative technologies, 5 (59), 314323.

4. Menkova, S.A. (2019). Formation of bases of self-organization at pupils of elementary school in educational activity. Scientific research: first steps: materials of the 73rd review of student research papers of the Department of Pedagogical, Social and Special Education. Irkutsk, (March 25-April 5).

5. The concept of the New Ukrainian school. (2016). URL: https://mon.gov.ua/storage/app/media/zagalna\%20serednya/nova-ukrainska-shkola-compressed.pdf (access date: 10.10.2020).

6. Pisarchuk, O.T. (2016). Preparation of the future primary school teacher for the organization of the educational and developmental environment: (Doctoral dissertation). Retrieved from Proquest Dissertations and Theses, Ternopil.

7. Pisarchuk, O.T. (2012). Features of the formation of the educational and developmental environment of preschool educational institutions. Scientific notes of Ternopil National Pedagogical University, 2, 44-51.

8. Rachenko, I.P. (1972). Scientific organization of pedagogical work. Moscow: Pedagogy.

9. Savchenko, O.Ya. (2012). Learning environment as a factor stimulating research activities of junior schoolchildren. Scientific notes of the Small Academy of Sciences of Ukraine, 1, 41-49.

10. Sergeenkova, O.P., Stolyarchuk, O.A., Kokhanova, O.P. \& Pasek, O.V. (2012). Age psychology: a textbook. Kyiv: LLC «Center for Educational Literature».

11. Smolyuk, S.V. (2017). Organizational and pedagogical conditions of formation of the developmental educational environment in the system of primary education of Ukraine (the end of the XX - the beginning of the XXI century). (Doctoral dissertation). Retrieved from Proquest Dissertations and Theses, Lutsk.

12. Smolyuk, S.V. (2016). Formation of the developmental educational environment of primary school in Ukraine in the XXI century: socio-cultural discourse. Pedagogical magazine of Volyn, 1 (2), 26-30.

13. Faleeva, L.V. (2012). Organization and self-organization as a personality trait: a comparative analysis of concepts. Modern problems of science and education, 4, 266-274.

13. Shevchenko, K.O. (2014). Pedagogical facilitation in the context of professional competence of a teacher. Scientific Bulletin of Mykolayiv National University named after V.O. Sukhomlynsky, 2 (13), 258263.

14. Yasvin, V.A. (2001). Educational environment: from modeling to design. Moscow: Smysl. 